Currículo sem Fronteiras, v. 19, n. 3, p. 1286-1304, set./dez. 2019

\title{
AS TEORIZAÇÕES CRÍTICAS NA EDUCAÇÃO AMBIENTAL DA ANPEd: tensionamentos e produções discursivas do GT 22
}

\author{
Lorena Santos da Silva \\ Universidade Federal do Rio Grande - FURG \\ Paula Corrêa Henning \\ Universidade Federal do Rio Grande - FURG
}

\begin{abstract}
Resumo
O presente artigo tem como propósito analisar os fundamentos filosóficos e epistemológicos da Educação Ambiental nas bases das teorias críticas. O material empírico desse estudo compõe-se de 26 trabalhos publicados nos anais do GT 22 da ANPEd, desde a $26^{\text {a }}$ Reunião Científica, ocorrida em 2003, até a $37^{\text {a }}$, realizada no ano de 2015. Utiliza-se das ferramentas teóricas e metodológicas documentos vistos como monumentos e formação discursiva, presentes no pensamento de Michel Foucault. Entende-se, assim, que os trabalhos selecionados produzem parte da formação discursiva que constitui a Educação Ambiental enquanto campo de saber. Com a análise dos trabalhosconstatou-se a recorrência de três eixos enunciativos: interdisciplinaridade, emancipação e transformação. Com as abordagens de cada uma das conceituações percebeu-se a forte correlação entre os esses três eixos para situar os objetivos e problematizações que a Educação Ambiental pode permear.
\end{abstract}

Palavras-chave: Educação Ambiental; ANPEd; Teoria crítica; Campo de saber.

\begin{abstract}
This article aims to analyze the philosophical and epistemological foundations of Environmental Education based on critical theories. The empirical material of this study is composed of 26 papers published in the annals of the ANPEd WG 22, from the 26th Scientific Meeting, held in 2003, to the 37th, held in the year 2015. Is used from Theoretical and methodological tools documents viewed as monuments and discursive formation, present in the work of Michel Foucault. It is understood, therefore, that the selected works produce part of the discursive formation that constitutes Environmental Education as a field of knowledge. With the analysis it was verified the recurrence of three enunciative axes: interdisciplinarity, emancipation and transformation. With the approaches of each one of the conceptuations the strong correlation between the three axes was perceived to locate the objectives and problematizations that the Environmental Education can permeate.
\end{abstract}

Keywords: Environmental Education; ANPEd; Critical theory; Field of knowledge.

ISSN 1645-1384 (online) www.curriculosemfronteiras.org 


\section{Introdução}

Com o fim da ditadura militar no Brasil, o país ansiava por mudanças no campo político, educacional e ambiental. O "milagre econômico" da década de 70, deu lugar aos questionamentos sobre a já denominada crise ambiental. Neste cenário vimos pouco a pouco o fortalecimento de discursos voltados à preocupação com o meio ambiente no âmbito internacional. O Brasil tardiamente foi pensar em tais questões, todavia seu movimento com a Educação Ambiental foi fortalecendo-se a ponto de ser uma questão vista como essencial para as esferas governamentais.

É a partir desse fortalecimento que vimos nascer um campo de saber tão potente intitulado Educação Ambiental. É sobre essa fabricação, marcadas por atravessamentos sociais, políticos, econômicos e culturais que esse artigo pretende tratar. A relação dos movimentos ambientalistas aos movimentos sociais reconfigurou as compreensões sobre os princípios e objetivos da Educação Ambiental. O fortalecimento desse campo deu-se em concomitância com os discursos das teorias críticas que buscam mostrar a potência eminentemente política da educação. Daí foi possível perceber que ao passo que a educação buscava distanciar-se do tecnicismo, a Educação Ambiental permeava os rastros de discursos que ansiavam não só pela politização do campo, mas por sua finalidade formativa na conscientização de sujeitos críticos e ativos, desejando modificar os contextos ambientais, sociais, culturais e políticos.

No final da década de 90 o fortalecimento científico da Educação Ambiental foi sendo cada vez mais evidente entre as Reuniões Científicas da Associação Nacional de PósGraduação e Pesquisa em Educação - ANPEd. A Educação Ambiental aparecia difundida entre diferentes Grupos de Trabalho - GTs, o que ocasionou em um intenso movimento dos/as pesquisadores/as para a criação do Grupo de Estudos - GE - voltado à Educação Ambiental. Com isso, em 2003, aconteceu o primeiro encontro do GE 22, que em 2005teve sua efetiva consolidação como GT 22 (ANPED, s/a).

Mediante sua consolidação no meio científico e a potência das teorias críticas na Educação Ambiental, buscamos seguir os rastros de parte da formação discursiva que constitui e legitima a Educação Ambiental enquanto campo de saber. Focando em seus fundamentos epistemológicos e filosóficos, buscamos, nesse artigo, compreender como os fundamentos filosóficos e epistemológicos da Educação Ambiental, a partir das teorias críticas, se constitui no GT 22 da ANPEd?

Entre os anos de 2003 a 2015 foram publicados 154 trabalhos nos anais da $26^{\text {a }}$ até a $37^{\text {a }}$ Reunião Científica. Do número total, encontramos 44 pesquisas que se debruçam sobre os fundamentos epistemológicos e filosóficos da Educação Ambiental, desses 26 baseiam-se nas teorias críticas. Sendo assim, temos como corpus empírico o número de 26 trabalhos publicados no recorte temporal de 2003 a 2015, cobrindo o primeiro encontro do GE 22 e o penúltimo do GT 22.

Amparamo-nos nos estudos de Michel Foucault como aporte teórico e metodológico dessa pesquisa. Partimos de duas ferramentas presentes na fase arqueológica do filósofo: Documentos vistos como monumentos e formações discursivas (FOUCAULT, 2015). 
Para Michel Foucault (2015) analisar as formações discursivas não se restringe a voltarse apenas para as enunciações concordantes e complementares, mas igualmente ampliar os horizontes de análise para formas distintas de compreender os fundamentos epistemológicos e filosóficos da Educação Ambiental que caminham para visões distintas entre as relações socioambientais. Compreendemos, portanto, que a Educação Ambiental é formada por diferentes perspectivas teóricas. As teorias críticas, nessa abordagem, são entendidas como parte da formação discursiva que constitui a Educação Ambiental enquanto campo de saber.

A Educação Ambiental é entendida, como como um campo de saber fabricado nas tramas de formações discursivas que produzem seu objeto, com a construção de conceitos e teorias, tornando-se visíveis em práticas sociais, pesquisas científicas, políticas públicas e documentos oficiais. Analisamos o campo, na confluência do pensamento de Maritza Maldonado (2012, p. 86) que vê a Educação Ambiental “[...] como um objeto histórico, ou seja, como um produto histórico de práticas discursivas e não discursivas; como uma invenção histórica e social”.

Na confluência da condição histórica na produção das formações discursivas, analisar os documentos na qualidade de monumentos, entendendo-os não como a tradução de uma determinada verdade que constitui o passado, mas, enquanto relações de poder e saber que estabelecem os jogos de diferenças discursivas que classificam os discursos em mais recorrentes, ou menos visíveis, em verdadeiros ou falsos. Nessa esteira, os trabalhos selecionados são vistos como enunciações que se materializam nos formatos de pesquisas científicas. São formas de conceituar, explicar e colocar em funcionamento alguns ditos sobre a Educação Ambiental.

[...] desde que existe uma disciplina como a história, temo-nos servido de documentos, interrogamo-los, interrogamo-nos a seu respeito; indagamos-lhes não apenas o que eles queriam dizer, mas se eles dizem a verdade, e com que direito podiam pretendê-lo, se eram sinceros ou falsificadores, bem informados ou ignorantes, autênticos ou alterados.[...] Ora, por uma mutação que não data de hoje, mas que, sem dúvida ainda não se concluiu, a história mudou sua posição acerca do documento: ela considera como sua tarefa primordial não interpretá-lo, não determinar se diz a verdade nem qual é seu valor expressivo, mas sim trabalhá-lo no interior e elaborá-lo: ela o organiza, recorta, distribui, ordena e reparte em níveis, estabelece séries, distingue o que é pertinente do que não é, identifica elementos, define unidades, descreve relações[...] (FOUCAULT, 2015, p. 7).

A escolha teórico-metodológica está em analisar o material empírico distante de um desejo de decifrar, determinar ou tornar visível a verdade imperativa, que configuraria a Educação Ambiental. O que nos propomos é examinar a formação discursiva que se compõe da recorrência de trabalhos fundamentados nas teorias críticas.

Na próxima seção mostramos as recorrências conceituais que constituem a forma com que os fundamentos filosóficos e epistemológicos da Educação Ambiental são compreendidos a partir das teorias críticas. Dentre as conceituações utilizadas, percebemos a 
predominância de três: interdisciplinaridade, emancipação e transformação. Na sequência apresentamos cada conjunto de extratos do material empírico para elucidar as bases empíricas que dirigem as análises realizadas.

\section{A finalidade interdisciplinar da Educação Ambiental no compromisso social de emancipar e transformar a sociedade}

Vemos, com maior potência, na década de 90 a formação de discursos muito contemporâneos que denotam ao campo da Educação Ambiental, uma finalidade mais ampla do que exclusivamente a preservação e conservação dos meios naturais. Articula-se ao compromisso social, entendendo que:

A educação ambiental como compromisso social não pode abrir mão da politização do debate ambiental, situando-o no terreno das doutrinas políticosideológicas e seus respectivos mecanismos de produção e reprodução social, trabalhando pelas condições ideais para os atores desvelarem a realidade a que estão submetidos com todas as suas contradições, percebendo a existência de situações de desigualdade, vulnerabilidade e risco ambiental, auxiliando-os a se instrumentarem na defesa de seus direitos e interesses, motivarem-se a reagir e participar para institucionalizar a justiça ambiental e mobilizarem-se de fato como sujeitos políticos na participação pública (LAYRARGUES, 2009, p. 28). [Grifo do autor]

As palavras de Phillippe Layrargues (2009), no que concerne aos objetivos do campo da Educação Ambiental, traduzem as discussões e compreensões dos 26 artigos publicados nos anais das Reuniões Científicas da ANPEd, no período de 2003 a 2015, que se baseiam nos fundamentos da Educação Ambiental denominada como "crítica, emancipatória e transformadora”. A politização da Educação Ambiental, nesta perspectiva, vincula-se a ideia de desvelar as ideologias dominantes que ofuscam as situações de dominados dos sujeitos em vulnerabilidade socioambiental. Essa intencionalidade atrelada ao campo, parte de uma base teórica relacionadas ao Materialismo Histórico Dialético marxista, utilizada como um dos fundamentos da teoria educacional de Paulo Freire. Nos trabalhos mapeados temos indicativos desta relação teórica, apresento-os em dois excertos que trouxemos abaixo.

É o pensamento marxista o principal referencial epistemológico da pedagogia crítica. Nele podemos encontrar um enorme, complexo e, por vezes, confuso, conjunto de idéias (sic) que emergem do pensamento de Marx (1818-1894) e de seu maior e mais constante parceiro intelectual Engels (1820-1895) (TOZONIREIS, 2003, p. 11).[Grifo nosso]

Distinguimos a Educação Ambiental como crítica preenchendo-a de sentido político; como uma ação política de transformação das relações dos homens entre 
si e deles com o ambiente, no sentido histórico. Para subsidiar este tipo de prática acreditamos na contribuição do referencial baseado na Teoria Crítica, com forte influência teórico-prática no pensamento marxista; ou seja, no materialismo histórico dialético (OLIVEIRA, 2011, p. 5). [Grifo nosso]

Assim como na educação, Paulo Freire é um autor de grande potência também no campo da Educação Ambiental. Seus estudos foram abraçados por educadores/as ambientais que se debruçam sobre a possibilidade de transpor os limites das disciplinas, dos currículos descontextualizados, das consciências oprimidas e das contradições encobertas pela ideologia dominante. Esta correnteza epistemológica se mostra presente em pesquisas que se debruçam sobre a Educação Ambiental, principalmente, em espaços formais e não formais. A existência das concepções presentes nas obras do autor para a construção do Tratado de Educação Ambiental para Sociedades Sustentáveis e Responsabilidade Global (BRASIL, 2014), não se findou na década de 90, pelo contrário, perpetuou-se entre pesquisadores que se dedicam ao enfronhamento das questões ambientais às educacionais. Isso tudo aponta para compreender o grande número de trabalhos aprovados que se utilizam das conceituações, problematizações e visões que tomam a interdisciplinaridade, a emancipação e a transformação social como eixos indispensáveis para se pensar a Educação Ambiental “crítica, transformadora e emancipatória”.

Antes de nos determos a apresentar a forma com que as teorias críticas são tratadas nos trabalhos mapeados, julgamos importante justificar, a partir de uma abordagem quantitativa, inicialmente, o número de pesquisas que acionam teoricamente os conceitos de interdisciplinaridade, emancipação e transformação. Tais eixos foram escolhidos por mostrarem-se mais recorrentes no corpus empírico selecionado.

No que concerne a noção da interdisciplinaridade, no GT 22, nove (9) trabalhos a utilizam como forma discutir uma abordagem crítica da Educação Ambiental. Tal conceito se articula tanto com a vontade de emancipar o sujeito, proposição utilizada em metade dos trabalhos selecionados (13), bem como, com a indispensabilidade de transformar as relações socioambientais (21). O que interessa, nesta amostra quantitativa, é que esses três conceitos não se apresentam de forma isolada, mas articulados no interior de uma ordem de pensamento que em um âmbito pedagógico discute a interdisciplinaridade, e em alguns casos, sua junção à transdisciplinaridade para a possibilidade de conscientizar os sujeitos a fim de que estes possam desvencilharem-se de uma visão ideologicamente manipuladora da realidade em que estão inseridos. A emancipação da ordem ideológica capitalista é inevitável para que coletivamente os sujeitos ajam em esferas políticas e governamentais.

Como o recorte do material de análise deu-se a partir de trabalhos que tomam por temática as esferas epistemológicas e filosóficas da Educação Ambiental, é compreensivo que a interdisciplinaridade seja menos presente, uma vez que, tal discussão se apresenta com maior ênfase em pesquisas cujo objetivo está na esfera formal do campo. Apesar de seu número menor em comparação aos demais eixos (emancipação e transformação socioambiental), não é possível descartá-la como fora da formação discursiva que constitui o campo de saber da Educação Ambiental, pelo motivo de visualizar a correlação que a 
interdisciplinaridade e transdisciplinaridade possuem com a emancipação e transformação. Sobre este assunto Ronaldo de Castro (2009, p, 173) afirma que:

A educação ambiental constitui uma área de conhecimento eminentemente interdisciplinar, em razão dos diversos fatores interligados e necessários ao diagnóstico e à intervenção que pressupõe. Nesse sentido, a educação ambiental não pode ser concebida apenas como um conteúdo escolar, pois implica uma tomada de consciência de uma complexa rede de fatores políticos, econômicos, culturais e científicos. [Grifo do autor]

Na continuidade do pensamento exposto pelo autor, é possível ponderar que a interdisciplinaridade se junta a noção transdisciplinar ao considerar os "[...] fatores políticos, econômicos, culturais e científicos” (IDEM) [Grifo do autor]. A aproximação das condições interdisciplinares e transdisciplinares da Educação Ambiental são expostas nas pesquisas científicas como parte eminente de um projeto político e educacional cujo objetivo pauta-se na emancipação dos sujeitos e na transformação da realidade socioambiental. Algumas citações ponderam a interdisciplinaridade sob o viés da aproximação de diferentes áreas do conhecimento científico com saberes locais e tradicionais. Trouxe alguns exemplos abaixo:

[...] é preciso reconhecer a necessidade da produção de conhecimento sobre Educação Ambiental que leve em conta a relação trabalho, meio ambiente e educação, dada a lacuna na pesquisa sobre a temática, considerando a interdisciplinaridade necessária à compreensão de uma realidade com múltiplas determinações (DELUIZ \&NOVICKI, 2004, p.13). [Grifo nosso]

A proposta interdisciplinar da Educação Ambiental é justamente a superação do reducionismo disciplinar. Apenas a articulação entre disciplinas não bastaria, pois pressupõe uma atitude interdisciplinar, uma maleabilidade dos espíritos (TRISTÃO, 2004, p. 12). [Grifo nosso]

Na última década, a EA tem sido pauta de diversas pesquisas, muitas, questionando as identidades que vêm sendo construídas e outras problematizando sua perspectiva em diferentes áreas, pois, ao pretender um "fazer interdisciplinar”, oportuniza o diálogo com diferentes áreas do conhecimento, abrindo um leque de interações sociais (GONÇALVES \&DIAS, 2005, p.1). [Grifo nosso]

Sendo assim, pensar em Educação Ambiental nesta abordagem dialógica, ecorelacional, freireana, significa atender aos princípios da inter/transdisciplinaridade; da resolução de questões ambientais concretas que carregam em si uma teia abrangente de problemas biofísicos, psíquicos, ecológicos, espirituais, éticos, morais, estéticos; da leitura de uma realidade que se constitui em rede de potencialidades; da multidimensionalidade humana; da noção de integralidade, inteireza; do foco nas múltiplas relações; da ecopráxis 
enquanto práxis ampliada por uma holo leitura política e social de mundo (FIGUEIREDO, 2006, p.14). [Grifo nosso]

\section{Em síntese, partindo da perspectiva interdisciplinar, seja na produção de conhecimento e/ou no processo de ensino-aprendizagem, transitando entre saberes científicos, populares e tradicionais, a EA Crítica busca mecanismos para que o indivíduo e a coletividade assumam uma postura reflexiva frente à problemática ambiental e busquem elementos para a consolidação de uma sociedade sustentável (SILVA, 2007, p.3). [Grifo nosso]}

Por via da análise dos excertos acima foi possível concluir que, a interdisciplinaridade se faz presente na esfera pedagógica, mas não se resume a essa, perpetua-se enquanto questão epistemológica, política e cultural. Nisso, a Educação Ambiental, muito a partir da articulação dos movimentos sociais e educacionais aos ambientais, envolve-se na discussão contrária ao fracionamento do conhecimento, quanto também na posição política e governamental que a interdisciplinaridade assumiu na sociedade brasileira. É viável compreender que antes de uma posição unicamente pedagógica, a interdisciplinaridade atravessa outras esferas mais amplas.

Principalmente a partir de meados do século XX, tornou-se cada vez mais difundida e forte um tipo de crítica à Ciência: passou-se a atribuir ao conhecimento científico uma boa parte dos males da Modernidade, senão mesmo a possibilidade de que esse tipo de conhecimento leve a espécie humana à barbárie total, ou até mesmo leve ao extermínio a vida no planeta (VEIGA-NETO, 1996, p. 19).

Ao analisar a difusão da prática discursiva pela interdisciplinaridade o autor nos trouxe pistas para pensar que, assim como a interdisciplinaridade, a Educação Ambiental também ganha força em um cenário de crise epistemológica, ambiental, social e cultural. São formações discursivas que emergem de uma vontade de modificar, substituir ou repensar as condições nas quais nos constituímos a partir de um pensamento metafísico. A visão de progresso as custas da exploração da natureza, das desigualdades e injustiças socioambientais se apresentam como “[...] males da Modernidade [...]” (IDEM). Não pusemos em questão a condição de emergência do campo de saber da Educação Ambiental, uma vez que não é esse o objetivo desse estudo, mas pensar nas condições de possibilidade que ocasionaram na preocupação com a relação ser humano-natureza, em um aspecto mais amplo, a circulação de enunciações que se firmam na relevância de considerar os saberes sociais, culturais e científicos para constituir uma prática discursiva da Educação Ambiental, como mostram as citações extraídas do corpus empírico.

A interdisciplinaridade é posta, nos trabalhos analisados, como parte integrante de uma posição que considera a multiplicidade das relações que se cruzam entre o meio ambiental, cultural, econômico, político, educacional e social. Multiplicidade que precisa ser vista, compreendida, tomada como relevante para que as ações sobre as questões de cunho 
socioambiental possam ser percebidas e resolvidas pelos sujeitos. Trata-se de uma posição que tem por finalidade um ensinamento, um tratar reflexivo de tais questões que necessitam ser resolvidas. Há uma finalidade, um objetivo a ser alcançado, uma tarefa a ser cumprida, posicionamento que alicerça um dos objetivos da educação, da escolarização das massas, pensadas e calcadas no contexto da Modernidade.

As noções extraídas do material empírico sobre a interdisciplinaridade trazem as marcas de um modo de pensar muito particular de um posicionamento teórico: as teorias críticas. Os conceitos de diálogo, leitura da realidade, consolidação de outro modo societário por meio da modificação individual e da ação coletiva pertencem a um bojo enunciativo da Educação Ambiental caracterizada como crítica.

A EA (crítica) pode ser compreendida como uma filosofia da educação que busca reorientar as premissas do pensar e do agir humano, na perspectiva de transformação das situações concretas e limitantes de melhores condições de vida dos sujeitos - o que implica mudança cultural e social (TORRES, FERRARI \& MAESTRELLI, 2014, p. 14). [Acréscimo dos autores]

Conforme apresentam os autores acima, a Educação Ambiental crítica tem por permissa a atuação transformadora das relações sociais, econômicas, culturais e ambientais, a partir da interação humana. Tal concepção ampara-se nas teorias críticas, cujas formulações e reflexões estão ancoradas em representantes da Escola de Frankfurt, que fortemente baseiase no pensamento de Karl Marx. De um modo geral, entre os trabalhos selecionados(26) é possível destacar enunciações recorrentes entre eles: Busca pela construção de uma sociedade mais igualitária e menos degradante; Transformação socioambiental; Formação de sujeitos com plena cidadania; Educação Ambiental como processo emancipatório; Crítica a produção capitalista; Embasamento teórico em Karl Marx e Paulo Freire; Preocupação com uma ordem autoritária; Crítica à dicotomia entre sociedade e natureza e Crítica ao trabalho alienador.

Continuando com a análise das pesquisas científicas mapeadas nos anais da ANPEd, passamos a considerar outro eixo enunciativo de grande potência e recorrência para as teorias críticas na Educação Ambiental, referimo-nos a questão da emancipação do sujeito. Antes de qualquer consideração mais aprofundada, julgamos importante trazer citações do corpus empírico selecionado que mostram os meios pelos quais a emancipação dos sujeitos é tomada, bem como sua intenção na/para a Educação Ambiental. Vejamos:

O que a Educação Ambiental propõe é uma teoria comprometida com a emancipação dos sujeitos, com a transformação da realidade socioambiental. A teoria é importante porque nos ajuda a compreender a prática, não porque seja superior à prática como durante muitos anos nos fez acreditar a ciência moderna (TRISTÃO, 2004, p.12). [Grifo nosso]

Em nossa análise das coleções, vemos que o livro de História está mudando e buscando se modernizar para atender aos PCN e conseguir uma boa classificação pelo MEC. Porém, muito precisa ser feito para que efetivamente o livro 
didático atue com eficácia na formação de cidadãos conscientes e críticos (SOARES\&NOVICKI, 2006, p. 9). [Grifo nosso]

[...] a pedagogia crítica diz respeito à teoria e a prática do processo de apropriação de conhecimentos, idéias, conceitos, valores, símbolos, habilidades, hábitos, procedimentos e atitudes para a emancipação dos sujeitos e a transformação das relações de dominação nas sociedades desiguais (TOZONI-REIS, 2007, p.4). [Grifo nosso]

A atividade docente, numa visão emancipadora, deve construir comunidades de aprendizagem, desenvolver capacidade para reflexibilidade, inovação, flexibilização e combater problemas criados pela sociedade capitalista, tais como o consumo excessivo, a perda da noção de comunidade e o distanciamento crescente entre as classes sociais superando a distância entre teorias ideais e práticas cotidianas [...] (SOARES, 2009, p. 14). [Grifo nosso]

Ao elaborarmos estes argumentos relacionados à participação e à educação ambiental crítica, queremos ressaltar que cabe à Educação Ambiental a perspectiva da emancipação humana. Contribuir para o entendimento de que o atual estado crítico do mundo pela insolvência das relações, a condição fragmentária e dicotômica entre ser humano-sociedade-natureza é produção e produzida e ideologicamente reproduzida pelo modo de produção capitalista (OLIVEIRA, 2011, p.10). [Grifo nosso]

Na proposta de uma EA crítica, a preocupação com as dimensões éticas e políticas são essenciais. A mudança de comportamentos individuais é substituída pela construção de uma cultura cidadã e na formação de atitudes ecológicas, que supõe a formação de um sentido de responsabilidade ética e social. Dessa forma, a EA Crítica busca mecanismos para que o indivíduo e a coletividade assumam uma postura reflexiva frente à problemática ambiental e busquem elementos para a consolidação de uma sociedade sustentável [...] (SILVA, 2013, p. 14). [Grifo nosso]

Nesse sentido, percebe-se que tanto a EA quanto a EP (Educação Popular) compartilham de um mesmo compromisso decorrente de um momento histórico de luta, de fazer da educação um espaço de tomada de consciência das situações econômicas, sociais e ambientais. Com raízes em um projeto educativo de ideais emancipadores, a educação aí toma um lugar de construção de conhecimentos a partir do saber, da cultura, da vida dos sujeitos envolvidos, tornando-os autores de sua própria história (GOMES, 2015, p. 15). [Acréscimo nosso] [Grifo nosso]

A emancipação dos sujeitos é abordada, nas pesquisas científicas, como um objetivo educativo que confronta o poder hegemônico, singularizado pelos meios de produção capitalista. Não é qualquer sujeito que precisa ser emancipado, esse é marcado por sua 
condição de dominado. Na busca por emancipá-los prepondera a ideia de que esses precisam perceber-se e constituir-se como cidadãos politicamente participativos e conscientes de sua condição para que seja possível uma mudança das relações sociais, ambientais, econômicas, educativas e políticas.

Nesse escopo, a emancipação, apresenta-se a partir de quatro prerrogativas que caracterizam a enunciação da Educação Ambiental enquanto ação emancipadora, são elas: Função de uma prática pedagógica; Articulação entre teoria e prática; Esclarecimento das consciências; E por fim, integração entre ser humano e natureza.

Ao referir-me à emancipação enquanto finalidade de uma prática pedagógica, evidentemente não desconsideramos sua carga epistemológica e filosófica, ao contrário disso, vimos a emancipação como uma vontade eminentemente educativa que têm por base a compreensão das relações sociais a partir dos estudos de Karl Marx. É possível ver a aproximação com as ideias de luta das classes sociais, da compreensão das formações econômicas da sociedade capitalista como condições históricas constituidoras dos sujeitos, ou mesmo, da relação do trabalho como processo criativo, não submetido a lógica do lucro.

A segunda consideração, vem ao encontro dessa primeira, a ideia de que teoria e prática precisam ser articuladas é encontrada nos estudos de Paulo Freire. Ao referir-se à necessidade de relacionar teoria e prática, tornando-se práxis, atravessa o compromisso da formação de sujeitos que refletem sobre as ações, buscando a transformação da sociedade. Para Paulo Freire (1987, p. 38) "A práxis, porém, é reflexão e ação dos homens sobre o mundo para transformá-lo. Sem ela, é impossível a superação da contradição opressor-oprimido”. Assim, foi possível perceber a finalidade epistemológica, pedagógica e filosófica da emancipação, a partir da articulação de dois polos vistos como separados, que precisam ser relacionados.

Não há emancipação sem o esclarecimento da consciência. Perceber a condição de dominados, das relações socioambientais orientadas pela ideologia do lucro capitalista; o estado de crise, seja ele abordado como ambiental ou civilizatório; as relações de desigualdade social e ambiental, são algumas das condições apresentadas no corpus empírico como indispensáveis para uma proposta de Educação Ambiental com objetivos emancipadores. Nisso, a tomada de consciência é uma questão central para a construção de um projeto societário justo, igualitário e sustentável. O bem-estar humano e não humano depende da consciência humana, "[...] entendida como um estado a que se pode chegar pelo uso correto da razão” (VEIGA-NETO, 2002, p. 25).

Nos trabalhos analisados, a polarização entre teoria e prática, é assumida a partir da prerrogativa de que se faz necessário, através da práxis, articulá-las para que a emancipação dos sujeitos oprimidos aconteça. Lidamos com uma noção de sujeito que no caminho de uma educação crítica consegue libertar-se das relações de poder. O poder, assim, é tomado como algo pertencente a uma minoria, algo negativo que oprime e aliena.

Outra finalidade atribuída à emancipação constitui-se na integração entre ser humano e natureza. Como podemos perceber ao longo das explicitações sobre a ação emancipatória é que essa intenciona alcançar diferentes fins no campo da Educação Ambiental, isso porque baseia-se na proposição de ações que viabilizem mudanças no âmbito individual e coletivo. O ser humano é entendido como uma extensão da natureza. 
A dicotomia entre ser humano e natureza acontece na mercantilização dessa, seu valor passa a ser socialmente atribuído como troca, daí floresce a exploração do ser humano e da natureza e a consequente dicotomia entre ambos. Assim, segundo Karl Marx (2004, p.87) "Todo auto-estranhamento (Selbstentfremdung) do homem de si e da natureza aparece na relação que ele outorga a si e à natureza para com os outros homens diferenciados de si mesmo" [Acréscimo do autor] [Grifo do autor]. O estranhamento, a que se refere o autor, é o resultado da relação do trabalho não criativo que distancia ser humano e natureza.

O modelo de produção capitalista é entendido como principal responsável pela condição de separação entre ser humano e natureza. Tornar visível a ideologia reproduzida por esse modo de produção, exige o esclarecimento e o desvelamento das relações ideologizadas. Voltamos a importância do esclarecimento das consciências e da articulação entre teoria e prática, para que seja possível emancipar-se e perceber-se enquanto parte da natureza, tendo assim posturas ecológicas e políticas que vão de encontro ao sistema econômico vigente, possibilitando a efetivação do processo de transformação de uma sociedade em crise para uma sustentável.

É justamente sobre a transformação social que a partir de agora detivemos nossa atenção e análise. Como estamos metodologicamente organizando, primeiramente apresento um conjunto de excertos das pesquisas aprovadas nas Reuniões Científicas da ANPEd. Seguem abaixo:

As abordagens crítico-dialéticas têm como categoria epistemológica fundamental a práxis (reflexão-ação-reflexão), pois objetivam a transformação social. A relação causal revela-se na inter-relação entre os fenômenos (lei da interdependência universal), inter-relação entre o todo e as partes e vice-versa, inter-relação da tese com a antítese, inter-relação dos elementos da estrutura econômica com os da superestrutura social, política, jurídica e intelectual etc (NOVICKI, 2003, p. 4). [Acréscimo do autor] [Grifo nosso]

Na perspectiva de uma Educação Ambiental crítica, torna-se fundamental discutir as várias concepções de desenvolvimento econômico em disputa e as matrizes discursivas que as fundamentam (ideologias, valores, comportamentos), tendo em vista a superação da alienação homem-natureza e a construção de um modelo alternativo de desenvolvimento contrahegemônico, apoiado na "sustentabilidade democrática" e na superação da desigualdade e da exclusão social, que se reflita nas concepções e práticas educacionais (DELUIZ \& NOVICKI, 2004, p. 12). [Acréscimo dos autores] [Grifo nosso]

[...] entendemos que a EA captada pelo ponto de vista da análise institucional, pode não ser um simples discurso ingênuo, comprometido e belo sobre a questão ambiental, mas sim um discurso repleto de conflitos, paradoxos, que escamoteiam um jogo oculto de forças e de poder, que tem como principal objetivo a implementação de uma sociedade com diferentes valores no que 
diz respeito às nossas relações com o meio ambiente (SÁNCHEZ \& VASCONCELLOS, 2010, p. 12). [Grifo nosso]

Distinguimos a Educação Ambiental como crítica preenchendo-a de sentido político; como uma ação política de transformação das relações dos homens entre si e deles com o ambiente, no sentido histórico. Para subsidiar este tipo de prática acreditamos na contribuição do referencial baseado na Teoria Crítica, com forte influência teórico-prática no pensamento marxista; ou seja, no materialismo histórico dialético. O método dialético busca a construção de uma visão integradora de ciência e filosofia, informando uma atuação transformadora das relações sociais (OLIVEIRA, 2011, p.5). [Grifo nosso]

No entanto, consideramos que a educação ambiental crítica visa propiciar uma leitura de mundo mais complexa, que contribua no processo de transformação de uma realidade que historicamente se coloca em uma crise socioambiental. A partir da compreensão gerada nesse processo, nós entendemos que ao buscar a transformação dos sujeitos, a abordagem da fenomenologia hermenêutica seja 'compatível' com uma educação ambiental crítica, emancipatória, transformadora, potencializando a ação dos atores sociais para uma melhor qualidade de vida (IARED, TULLIO\&OLIVEIRA, 2012, p.1). [Grifo nosso]

Diversas publicações, entre elas governamentais, têm buscado definir e defender um paradigma crítico-transformador da educação ambiental de modo a desenvolver uma análise e ação social sobre as complexas problemáticas socioambientais, entre as quais podem ser inseridos os riscos de desastres naturais. Essa educação ambiental 'crítico-transformadora-emancipatória' baseia-se em processos que discutem a organização da sociedade moderna e seus impactos sobre a socio-bio-diversidade, em oposição a uma concepção educacional conteudista e comportamentalista, baseada na transmissão de conhecimentos científicos sobre o ambiente e comportamentos ambientalmente adequados [...] (SULAIMAN \& JACOBI, 2013, p.7). [Grifo nosso]

A educação ambiental, como componente de uma cidadania abrangente, está relacionada com uma nova forma da relação homem/natureza. Assim, a Educação Ambiental se constitui como um ato político voltado para a transformação social e representa um instrumento essencial para superar os atuais impasses da nossa sociedade. Esta mesma intencionalidade que orienta a EA como parte essencial da formação cidadã dialoga com uma Educação Popular pensada como um instrumento de emancipação dos oprimidos, posto que a opressão da natureza tem se manifestado historicamente como a outra face da opressão humana (GOMES, 2015, p.11). [Grifo nosso] 
É inexorável a presença do desejo de transformar as relações sociais, cada trabalho apresenta sua discussão e consequentemente sua justificativa para que a transformação social, econômica, democrática ou ambiental aconteça. Transformar o modelo de produção capitalista aparece como predominante entre as pesquisas. No entanto, é possível perceber que ao longo das Reuniões Científicas da ANPEd, do período de 2003 a 2015, essa enunciação foi unindo-se a outras. A imprescindibilidade de transformar os meios de produção capitalista foi se atrelando a outras enunciações que também preponderam o objetivo da Educação Ambiental de transformar. Diante disso, a pergunta a ser respondida, a partir dos trabalhos mapeados é: O que a Educação Ambiental, fundamentada nas teorias críticas, deve transformar? Foi na tentativa de dar indícios que possam responder a essa pergunta, que nos dedicamos nos próximos parágrafos.

Os excertos demonstram que a ideia de transformação dos meios de produção foi sendo articulada a outras transformações, tais como: Transformação das relações entre ser humano e natureza, das desigualdades sociais, da crise ambiental, da abordagem epistemológica, filosófica e pedagógica da educação, assim como, dos valores éticos e morais. Transformações essas, igualmente vistas como necessárias a uma Educação Ambiental crítica. Tudo isso, sem desconsiderar a indispensabilidade de transformar o sistema econômico.

As articulações citadas acima, não supõem que as enunciações referentes à transformação tenham perdido seu valor, aliás, justo o contrário! Como nos ensinou Michel Foucault (2015), as formações discursivas não são estanques, ou seja, estão em conformidade com outros sistemas de formação que exigem a presença de outros enunciados para dar conta de novas problemáticas que vêm sendo aderidas ao campo de saber da Educação Ambiental. Sobre isso Michel Foucault (2015, p. 79), nos alerta que:

Uma formação discursiva não ocupa, assim, todo o volume possível que lhe abrem por direito os sistemas de formação de seus objetos, de suas enunciações, de seus conceitos; ela é essencialmente lacunar, em virtude do sistema de formação de suas escolhas estratégicas. Daí o fato de que, uma vez retomada, situada e interpretada em uma nova constelação, uma dada formação discursiva pode fazer aparecerem possibilidades novas [...]

As enunciações que visam a transformação do sistema capitalista vão sendo ajustada e imiscuída a outras enunciações que também estão na ordem do verdadeiro. Esse ajustamento enunciativo muito antes de diminuir a potência da ação transformadora, da Educação Ambiental, reativa suas forças nos acontecimentos que fomentam outras transformações, como as epistemológicas, sociais, culturais e éticas, sem desconsiderar a transformação do sistema econômico, o que longe de diminuir sua potência a fortalece para abranger outros objetos e temas de pesquisa.

Isso nos mostra os movimentos conceituais e estratégicos que intencionalmente constituem uma determinada formação discursiva. Assim é que não estamos lidando com a perda de potência de uma enunciação, mas da junção dessas com outras, o que gera um outro 
sistema enunciável, que não perde completamente suas características, reconfigura-se numa trama de acontecimentos históricos.

A relevância da transformação do sistema de produção capitalista é considerada mais fortemente para a consolidação de um outro modo de vida, diferente do que o capitalismo consolidou. A apropriação desenfreada dos recursos naturais e a natureza, vista como mercadoria de troca, é uma questão relevante para que a Educação Ambiental possa modificar tais relações que separam ser humano e natureza na formação de uma ideologia dominante que visa o lucro. A separação entre a humanidade e a natureza se dá através do trabalho alienado que desumaniza e exprime sem receio os recursos naturais.

O início da transição do sistema Feudal para o sistema Capitalista no século XVI, foi marcado por acontecimentos no âmbito epistemológico, político, cultural e social, que deram condições de possibilidade para a consolidação do Capitalismo no século XVIII. Salientamos, aqui, a importância dos acontecimentos da ciência, nos modos de olhar para a natureza e posicionar o ser humano como sujeito do conhecimento, que demarcaram no início da transição Feudalismo-Capitalismo e a separação hierarquizada entre ser humano e natureza. Nas palavras da autora, abaixo, vê-se as primeiras manifestações dos modos de produzir conhecimento, que ocorrem no mesmo período histórico da transição de modelos econômicos distintos.

Os acontecimentos acerca da ciência a que me refiro aqui destinam-se a olhar para a revolução científica que tivemos na virada do século XVI para o XVII, e que vem apresentando sinais de enfraquecimento. Vale referir que esta revolução teve início em 1543, com a publicação do De Revolutionibus de Copérnico, e, em 1687, com a publicação dos Principia, momento fértil de produção de novos conhecimentos e nova visão de mundo. No entanto, a virada epistemológica foi mais decisiva no final do século XVII, com os estudos de Isaac Newton. Além disso, não é possível deixar de comentar que, nas quatro primeiras décadas do século XVII, aparecem os trabalhos seminais de Galileu e de Kepler, de importância decisiva para o processo da revolução científica (HENNING, 2012, p. 488).

O que gostaríamos de evidenciar é que, a passagem de uma episteme clássica para uma episteme moderna, foi um dos acontecimentos que igualmente influenciaram na separação e hierarquização entre cultura e natureza. Portanto, o sistema econômico pode ser visto como não sendo o único responsável por essa visão. Há uma variedade de acontecimentos que poderiam ser descritos. Não cabe aqui ressaltá-los, uma vez que necessitaria de uma outra pesquisa científica para demarcar uma genealogia da separação entre ser humano e natureza.

Voltando para o conceito de transformação nos trabalhos mapeados, vimos que o pensamento marxista se faz presente junto ao referencial crítico para demarcar a importância da "[...] construção de uma visão integradora entre ciência e filosofia [...]" (OLIVEIRA, 2011, p.5) para a efetivação da transformação das relações socioambientais. Como anteriormente dito, não se trata de dizer que o sistema econômico deixou de ser relevante 
para as pesquisas de cunho crítico, mas que há uma abertura para abordagens mais abrangentes no campo da Educação Ambiental.

Neste cerne em que apoiamos as análises, trouxemos uma questão que teoricamente ressaltou nossa atenção: a tentativa de aproximar a Educação Ambiental crítica, como processo de transformação da crise socioambiental, da abordagem fenomenológica e hermenêutica. Isso mostra a necessidade de diálogo com outras perspectivas teóricas sem que se abra mão das enunciações ligadas às teorizações críticas.

Tal aproximação teórica é inevitavelmente instigante, porém preocupante, uma vez que partem de filosofias diferentes. Enquanto as teorias críticas, embasam-se em uma filosofia da consciência, a perspectiva fenomenológica e a hermenêutica apoia-se na filosofia da linguagem. Segundo Arilene Maria Soares de Medeiros e Maria Auxiliadora de Resende Braga Marques (2003), a filosofia da consciência ampara-se por um interesse a priori, como por exemplo o uso dos conhecimentos para a emancipação dos sujeitos, a consciência baseiase em uma intencionalidade para o conhecimento, seja para dominação ou para emancipação. A filosofia da linguagem desloca-se desse interesse, no momento em que considera a relevância da compreensão, é o processo de argumentação e contra-argumentação que não busca o conflito, mas o consenso.

Encontramos ainda duas aproximações com a relação entre a Educação Ambiental e o conceito de transformação. As temáticas que realizam tal articulação amparam-se na possibilidade de reverter os riscos e desastres naturais e superar a separação entre ser humano e natureza. O caráter transformador da Educação Ambiental, de abordagem crítica, tem por objetivo o desenvolvimento de análise e ação política que constituam uma cidadania plena, que ultrapassem as atitudes sustentáveis, sem uma discussão plena dos aspectos sociais, políticos, ambientais, científicos, filosóficos e sociais, que atinja as esferas governamentais. Essas enunciações se mostram próximas ao que caracterizam a interdisciplinaridade e emancipação dos sujeitos.

De um modo geral, entre os três eixos de análise - interdisciplinaridade, emancipação e transformação - há uma confluência enunciativa em diferentes temas envolvendo a Educação Ambiental, quais sejam: institucionalização escolar, risco ambiental, aproximações com Paulo Freire, alfabetização de jovens e adultos em uma cooperativa de resíduos sólidos, filmes, práxis pedagógica, natureza, mudanças climáticas. Tais temas são tomados como escopo dos estudos, trazendo conceituações que dão corpo ao que tem se entendido por Educação Ambiental nas linhas teóricas críticas.

Nos trabalhos analisados não houve a possibilidade de olhar para a interdisciplinaridade sem considerar a emancipação e a transformação. Existe uma correlação entre esses três eixos que se apresentam como características potentes e fortemente circulantes na formação de uma Educação Ambiental de perspectivas críticas.

A finalidade de emancipar o sujeito relaciona-se com a possibilidade de ação; emancipar tem sua finalidade. A humanização do ser humano, o pensar criticamente sobre o sistema econômico capitalista que reflete, nesta perspectiva das teorias críticas, nas conjunturas sociais e ambientais são condições para que ocorra a transformação dos meios de produção, 
das relações de desigualdade social, da educação, das injustiças ambientais e da própria sociedade.

\section{Considerações Finais}

Diante desses três elementos que mapeamos nos trabalhos e procuramos dar visibilidade, entendemos que as teorias críticas vêm sendo assumidas como uma perspectiva profícua para pensar a Educação Ambiental. A partir delas, os textos apresentados na ANPEd vêm mostrando parte da construção da seara ambiental e trazendo para discussão uma série de questões necessárias e pertinentes para o momento atual de preocupantes problemas ambientais que vivemos. O modo como essas discussões são feitas, muitas vezes, se atrelam a esses três elementos: interdisciplinaridade, emancipação e transformação.

Tal tríade, em dados momentos, apresenta-se nos materiais analisados, como conceitos de atuação e coexistência recíproca na produção da compreensão da Educação Ambiental de cunho crítico. A abordagem interdisciplinar, entendida não só como a correlação entre as disciplinas, mas também entre os saberes tradicionais e populares, apresenta-se consoante a possibilidade de conscientizar os sujeitos, garantindo sua emancipação através do pensamento crítico que desvela a ideologia dominante, que degrada e explora os seres humanos e a natureza. Sob essa ótica, a perspectiva interdisciplinar possibilita, assim, a emancipação dos sujeitos.

As perspectivas teóricas críticas apresentam-se como uma parte da formação discursiva que produz o campo de saber da Educação Ambiental, isso não quer dizer que não existam outros modos de compreender, conceituar e fundamentar as bases filosóficas e epistemológicas da Educação Ambiental. Retomemos os estudos de Michel Foucault (2015) para lembrarmo-nos que uma formação discursiva não se constitui da universalidade e concordância, mas das defasagens e diferenças conceituais, teóricas, filosóficas e epistemológicas.

\section{Referências}

ASSOCIAÇÃO NACIONAL DE PÓS-GRADUAÇÃO E PESQUISA EM EDUCAÇÃO. Histórico GT 22

Educação Ambiental. s/a. Disponível em: http://www.anped.org.br/sites/default/files/resources/ HIST_RICO_GT22_Educa_o_Ambiental.pdf. Acesso em 27 mar. 2018.

BRASIL.Tratado de Educação Ambiental para Sociedades Sustentáveis e Responsabilidade Global. In: BRASIL. Órgão gestor da PNEA. Ministério do Meio Ambiente. Ministério da Educação. Educação Ambiental por um Brasil sustentável: ProNEA, Marcos Legais \& Normativos. Brasília, 2014 b. Disponível em: http://www.mma.gov.br/publicacoes/educacao-ambiental/category/98-pronea. Acesso em: 28mar. 2018.

CASTRO, Ronaldo Souza de. A construção de conceitos científicos em educação ambiental. In: LOUREIRO, Carlos Frederico Bernardo; LAYRARGUES, Phillippe Pomier; CASTRO, Ronaldo Souza de (orgs.). Repensar a educação ambiental: um olhar crítico. São Paulo: Cortez, 2009. 
DELUIZ, Neise; NOVICKI, Victor. Trabalho, meio ambiente e desenvolvimento sustentável: Implicações para uma proposta crítica de educação ambiental. 2004. In: $27^{a}$ Reunião Científica da Associação Nacional de Pós-Graduação e Pesquisa em Educação. Disponível em: http://27reuniao.anped.org.br/gt22/t2210.pdf. Acesso em: 28mar. 2018.

FIGUEIREDO, João Batista. As contribuições de Paulo Freire para uma educação ambiental dialógica. 2006. In:29a Reunião Científica da Associação Nacional de Pós-Graduação e Pesquisa em Educação. Disponível em: http://29reuniao.anped.org.br/trabalhos/trabalho/GT22-2184--Int.pdf. Acesso em: 28mar. 2018.

FREIRE, Paulo. Pedagogia do Oprimido. 17 ed. Rio de Janeiro: Paz e Terra, 1987.

FOUCAULT, Michel. Arqueologia do Saber. 8ª ed. Rio de Janeiro: Forense Universitária, 2015.

GOMES, Dinorá de Castro. A confluência da educação ambiental com a educação popular na alfabetização de adultos trabalhadores em cooperativa de resíduos sólidos. 2015. In:37 ${ }^{\text {a }}$ Reunião Científica da Associação Nacional de Pós-Graduação e Pesquisa em Educação. Disponível em: http://37reuniao.anped.org.br/wpcontent/uploads/2015/02/Trabalho-GT22-4583.pdf. Acesso em: 28mar. 2018.

GONÇALVES, Ana do Carmo Goulart; DIAS, Cleuza Maria Sobral. Práticas educativas no contexto escolar e as manifestações dos princípios da educação ambiental. 2005. In: $\mathbf{2 8}^{\mathbf{a}}$ Reunião Científica da Associação Nacional de Pós-Graduação e Pesquisa em Educação. Disponível em:http://28reuniao.anped.org.br/?_ga=2.151015929.1917186005.1496960557-

1212691838.1493936843Acesso em: 28mar. 2018.

HENNING, Paula Corrêa. Resistência e Criação de uma Gaia Ciência em Tempos Líquidos. Ciência \& $\begin{array}{lllllllll}\text { Educação, } & \text { v. } & 18, & \text { n. } & 2 \text { 2, } & \text { p. 487-502, } & \text { 2012. } & \text { Disponível em }\end{array}$ http://www.scielo.br/pdf/ciedu/v18n2/a16v18n2.pdf. Acesso em: 19mar. 2018.

IARED, Valéria Ghisloti; TULLIO, Ariane Di; OLIVEIRA, Haydée Torres de. Uma aproximação entre Gadamer e Paulo Freire como contribuição para refletir sobre a pesquisa em educação ambiental. 2012. In: 35a Reunião Científica da Associação Nacional de Pós-Graduação e Pesquisa em Educação. Disponível em: http://35reuniao.anped.org.br/images/stories/trabalhos/GT22\%20Trabalhos/GT22-1395_int.pdf. Acesso em: $1^{\circ}$ jul. 2017.

LAYRARGUES, Philippe Pomier. Educação ambiental como compromisso social: o desafio da superação das desigualdades. In: LOUREIRO, Carlos Frederico Bernardo; LAYRARGUES, Phillippe Pomier; CASTRO, Ronaldo Souza de (orgs.). Repensar a educação ambiental: um olhar crítico. São Paulo: Cortez, 2009.

MALDONADO, Maritza Maciel Castrillon. A ordem do discurso da Educação Ambiental. Porto Alegre, 2001, 126 f. Dissertação (Mestrado em Educação). Universidade Federal do Rio Grande do Sul. Programa de Pós-Graduação em Educação. Disponível em: http://www.lume.ufrgs.br/handle/10183/96091. Acesso em: 17mar. 2018.

NOVICKI,Victor de Araujo. Abordagens teórico-metodológicas na pesquisa discente em educação ambiental: programas de pós-graduação em educação do Rio de Janeiro (1981-2002). 2003. In:26a Reunião Científica da Associação Nacional de Pós-Graduação e Pesquisa em Educação. Disponível em: http://26reuniao.anped.org.br/?_ga=2.51350505.1984736531.1498861634-1212691838.1493936843.

Acesso em: 28mar. 2018.

MARX, Karl. Manuscritos econômico-filosóficos. São Paulo: Boitempo Editorial, 2004.

MEDEIROS, Maria Soares de; MARQUES, Maria Auxiliadora de Resende Braga. Habermas e a teoria do conhecimento. Revista Educação Temática Digital. Campinas, v.5, n.1, p.1-24, dez. 2003. Disponível em: https://periodicos.sbu.unicamp.br/ojs/index.php/etd/article/view/627/642. Acesso em: 28mar. 2018.

OLIVEIRA, Aline Lima de. Contribuições da participação à práxis política e emancipatória em Educação Ambiental. 2011. In: 34 ${ }^{\text {a }}$ Reunião Científica da Associação Nacional de Pós-Graduação e Pesquisa em Educação. Disponível em: http://34reuniao.anped.org.br/images/trabalhos/GT22/GT22-547\%20int.pdf. Acesso em: 28mar. 2018. 
SÁNCHEZ, Celso; VASCONCELLOS, Hedy Silva Ramos de. A institucionalização da educação ambiental: uma perspectiva. 2010. 33 ${ }^{\text {a }}$ Reunião Científica da Associação Nacional de Pós-Graduação e Pesquisa em Educação. http://33reuniao.anped.org.br/33encontro/app/webroot/files/file/Trabalhos\%20em\%20PDF/GT22-6370-Int.pdf. Acesso em: 28mar. 2018.

SILVA, Rosana Louro Ferreira. O meio ambiente por trás da tela: concepções de educação ambiental dos filmes da tv escola. 2007. In: 30 Reunião Científica da Associação Nacional de Pós-Graduação e Pesquisa em Educação. Disponível em: http://30reuniao.anped.org.br/trabalhos/GT22-3678--Int.pdf. Acesso em: 28mar. 2018.

A educação ambiental frente às mudanças climáticas globais: contribuições da análise crítica da mídia. 2013. In: 36 Reunião Científica da Associação Nacional de Pós-Graduação e Pesquisa em Educação. Disponível http://36reuniao.anped.org.br/pdfs_trabalhos_aprovados/gt22_trabalhos_pdfs/gt22_3217_texto.pdf. Acesso em: 28mar. 2018.

SOARES, Andréa de Almeida Rosa; NOVICKI, Victor. Educação ambiental através de livros didáticos de história do segundo segmento do ensino fundamental. 2006. In: $\mathbf{2 9}^{\mathrm{a}}$ Reunião Científica da Associação Nacional de Pós-Graduação e Pesquisa em Educação. Disponível em: http://29reuniao.anped.org.br/trabalhos/trabalho/GT22-2378--Int.pdf. Acesso em: 28mar. 2018.

SOARES, Maria Lucia de Amorim. Entre a dupla determinação de homem e a revolução técnico: científica no campo da educação ambiental crítica. 2009. In: 32ª Reunião Científica da Associação Nacional de PósGraduação e Pesquisa em Educação. http://32reuniao.anped.org.br/arquivos/trabalhos/GT22-5165--Int.pdf. Acesso em: 28mar. 2018.

SULAIMAN, Samia Nascimento; JACOBI, Pedro Roberto. Os desafios e potencialidades da articulação entre educação ambiental e prevenção de desastres naturais no brasil. 2013. In: $\mathbf{3 6}^{\mathbf{a}}$ Reunião Científica da Associação Nacional de Pós-Graduação e Pesquisa em Educação. Disponível em: http://36reuniao.anped.org.br/pdfs_trabalhos_aprovados/gt22_trabalhos_pdfs/gt22_3060_texto.pdf. Acesso em: 28mar. 2018.

TORRES, Juliana Rezende; FERRARI, Nadir; MAESTRELLI, Sylvia Regina Pedrosa. Educação Ambiental crítico-transformadora no contexto escolar: teoria e prática freireana. In: LOUREIRO, Carlos Frederico Bernardo; TORRES, Juliana Rezende (orgs.). Educação ambiental: dialogando com Paulo Freire. São Paulo: Cortez, 2014.

TOZONI-REIS, Marília Freitas de Campos. Natureza, razão e história: Contribuições para uma Pedagogia da Educação Ambiental. 2003. In: $\mathbf{2 6}^{\mathrm{a}}$ Reunião Científica da Associação Nacional de Pós-Graduação e Pesquisa em Educação. http://26reuniao.anped.org.br/?_ga=2.124126026.1728742667.1496793583-1212691838.1493936843. Acesso em: 28mar. 2018.

Fundamentos teóricos para uma pedagogia crítica da educação ambiental: algumas contribuições. 2007. In: 30ª Reunião Científica da Associação Nacional de Pós-Graduação e Pesquisa em Educação. Disponível em: http://30reuniao.anped.org.br/trabalhos/GT22-3311--Int.pdf. Acesso em: 28mar. 2018.

TRISTÃO, Martha. Os contextos da educação ambiental no cotidiano: racionalidades da/na escola. 2004. In:27 Reunião Científica da Associação Nacional de Pós-Graduação e Pesquisa em Educação. Disponível em: http://27reuniao.anped.org.br/gt22/t229.pdf. Acesso em: 28mar. 2018.

VEIGA-NETO, Alfredo. A ordem das disciplinas. Porto Alegre, 1996. 344 f. Tese (Doutorado em Educação). Universidade Federal do Rio Grande do Sul. Programa de Pós-Graduação em Educação. Disponível em:http://www.lume.ufrgs.br/handle/10183/131158. Acesso em: 20mar. 2018.

Olhares. In.: COSTA, Marisa Vorraber (org). Caminhos Investigativos I: novos olhares na pesquisa em educação. RJ: DP\&A, 2002. p.23-38 


\section{Correspondência}

Lorena Santos da Silva: É Doutoranda e Mestre em Educação Ambiental pelo Programa de Pós-Graduação em Educação Ambiental.

Email: lory.lorenasantos@gmail.com

Paula Corrêa Henning: É Doutora em Educação pela Universidade do Vale do Rio dos Sinos. Professora associada I na Universidade Federal do Rio Grande. Bolsista Produtividade 2 do CNPq.

Email: paula.c.henning@gmail.com

Texto publicado em Currículo sem Fronteiras com autorização das autoras 